\title{
¿ES INCONSTITUCIONAL EL RECONOCIMIENTO DE EFECTOS SUPRARREGIONALES A LOS ACTOS HABILITANTES EN ESPAÑA? A PROPÓSITO DE LA STC 79/2017, DE 22 DE JUNIO
}

\author{
Javier GARCÍA LUENGO \\ Catedrático de Derecho Administrativo \\ Facultad de Derecho \\ Universidad de Oviedo \\ jgluengo@uniovi.es
}

\section{INTRODUCCIÓN}

La Ley 20/2013, de 9 de diciembre, de Garantía de la Unidad de Mercado, creó varios instrumentos destinados a fortalecer la libre circulación de personas, bienes y servicios en España cuya constitucionalidad, por vulnerar la distribución de competencias entre el Estado y las Comunidades Autónomas, fue puesta en entredicho por el Parlamento de Cataluña, siendo el objeto de la Sentencia del Tribunal Constitucional 79/2017, de 22 de junio.

Aunque nuestro comentario se va a centrar fundamentalmente en la problemática del reconocimiento de eficacia suprarregional, es conveniente hacer un breve repaso por los otros pronunciamientos que contiene esta importante resolución del Tribunal Constitucional, puesto que el contexto en el que el Tribunal de garantías analiza esa extensión de los efectos de los títulos habilitantes es también relevante a la hora de valorar el alcance de la solución concreta adoptada.

La primera cuestión planteada por el Parlamento de Cataluña en el recurso que el Tribunal resuelve en esta sentencia, era la supuesta inconstitucionalidad de la exigencia del art. 14.2 de la citada Ley 20/2013 de que todo proyecto de norma que afecte de manera relevante a la unidad de mercado deba ser incluido en un sistema electrónico de intercambio de información con la Administración del Estado y la de las demás Comunidades Autónomas, acompañado, en su caso, de la memoria de análisis de impacto normativo. La alegación del Parlamento de Cataluña contra esta 
previsión se basó en el argumento de que suponía el establecimiento de un control ex ante contrario a su autonomía política.

El Tribunal Constitucional rechaza este argumento al entender que el mecanismo es una manifestación adecuada del principio de coordinación y tiene por objeto favorecer la adecuada articulación del ejercicio de las respectivas competencias, sin constituir un control ex ante al tratarse de un mero mecanismo de información (FJ 3. ${ }^{\circ}$ de la Sentencia 79/2017).

En segundo lugar, el Parlamento de Cataluña discutía la constitucionalidad de las limitaciones que la Ley de Garantía de la Unidad de Mercado impone al sometimiento de actividades a limitaciones o prohibiciones y, muy concretamente, los obstáculos que la Ley establece al sometimiento de actividades a autorización, al exigir la aplicación a dicho sometimiento de una serie de limitaciones materiales importantes.

Concretamente, la Ley de Garantía de la Unidad de Mercado exige para someter a autorización una actividad que el poder público competente pueda alegar razones de interés público, «razones imperiosas de interés general» que están, además, tasadas en la Ley (art. 17.1) ${ }^{1}$, y el Parlamento de Cataluña veía en esa regulación una limitación inconstitucional de sus competencias, tanto porque se restringe la posibilidad de imponer el control mediante autorizaciones como por la restricción de los motivos de interés público que pueden justificar el uso de esta técnica de control.

La impugnación no tuvo éxito, ya que el Tribunal Constitucional consideró que la limitación de los motivos que pueden justificar el sometimiento

\footnotetext{
${ }^{1}$ El art. 17.1 de la Ley dispone que: «1. Se podrá establecer la exigencia de una autorización siempre que concurran los principios de necesidad y proporcionalidad, que habrán de motivarse suficientemente en la Ley que establezca dicho régimen. Cuando el régimen de autorización se exija por norma comunitaria o tratado internacional, las autorizaciones podrán estar previstas en una norma de rango inferior a la Ley. Se considerará que concurren los principios de necesidad y proporcionalidad para la exigencia de una autorización: a) respecto a los operadores económicos, cuando esté justificado por razones de orden público, seguridad pública, salud pública o protección del medio ambiente en el lugar concreto donde se realiza la actividad, y estas razones no puedan salvaguardarse mediante la presentación de una declaración responsable o de una comunicación; b) respecto a las instalaciones o infraestructuras físicas necesarias para el ejercicio de actividades económicas, cuando sean susceptibles de generar daños sobre el medio ambiente y el entorno urbano, la seguridad o la salud pública y el patrimonio histórico-artístico, y estas razones no puedan salvaguardarse mediante la presentación de una declaración responsable o de una comunicación; c) cuando por la escasez de recursos naturales, la utilización de dominio público, la existencia de inequívocos impedimentos técnicos o en función de la existencia de servicios públicos sometidos a tarifas reguladas, el número de operadores económicos del mercado sea limitado; d) cuando así lo disponga la normativa de la Unión Europea o tratados y convenios internacionales, incluyendo la aplicación, en su caso, del principio de precaución. Las inscripciones en registros con carácter habilitante tendrán a todos los efectos el carácter de autorización».
} 
de una actividad a limitaciones y, concretamente, a autorización o licencia previa se había realizado por el legislador estatal en términos muy amplios — razones de orden público, seguridad pública, salud pública o protección del medio ambiente- que no impiden al legislador autonómico desarrollar sus políticas. En concreto, el Tribunal señala que la enumeración de finalidades «es lo suficientemente abierta como para que las Comunidades Autónomas puedan desarrollar sus competencias y, por tanto, no se produzca tal restricción».

En cuanto a la limitación de la técnica autorizatoria en sí misma considerada, el Tribunal rechaza que estemos ante una restricción inconstitucional por limitativa de la autonomía, ya que entiende que pueden utilizarse otros instrumentos alternativos de intervención. En palabras del Tribunal: «La restricción de una determinada modalidad de intervención administrativa, la autorización, no pone en riesgo la garantía del nivel de protección de determinados objetivos legítimos a través de otras modalidades de intervención, y expresa una opción político-legislativa adoptada en el marco de la libertad de configuración que la Constitución atribuye al Estado a través del art. 149.1.1.13 CE. Es más, este título competencial ampararía no sólo la restricción de una determinada modalidad de intervención administrativa, sino también la fijación de una concreta modalidad de intervención, pues precisamente en la STC 139/2013, de 8 de julio, FJ 5, se dilucidaba la constitucionalidad de una previsión estatal que sustituía el régimen de autorización por el régimen de notificación al órgano autonómico correspondiente [...] El Estado puede, legítimamente, al amparo de sus competencias, en particular la relativa a la ordenación general de la economía ex art. 149.1.13 CE, fijar una determinada modalidad de intervención administrativa con la finalidad de dinamizar la actividad económica».

El razonamiento del Tribunal es plausible, aunque olvida otro elemento esencial que ampara la limitación de forma básica del uso de la técnica autorizatoria y es la necesidad de garantizar la libertad ${ }^{2}$. La imposición de la autorización como título habilitante de una actividad supone siempre una intromisión en la libertad de quienes quieran realizar dicha actividad, que tiene, en consecuencia, que ampararse en una norma legal y adecuar-

${ }^{2}$ La ausencia de toda perspectiva subjetiva en el razonamiento del Tribunal Constitucional en esta sentencia ya ha sido puesta de manifiesto, con plena razón, por el profesor Alfaro. Puede consultarse su comentario en J. Alfaro Águila-Real, «La sentencia del Tribunal Constitucional sobre la Ley de Unidad de Mercado», en bttp://almacendederecho.org/ la-sentencia-del-tribunal-constitucional-la-ley-unidad-mercado/. 
se a las exigencias del principio de proporcionalidad en sentido amplio, como impone la propia Ley 20/2013, de 9 de diciembre, de Garantía de la Unidad de Mercado. Esta limitación de la libertad se muestra en el hecho de que cualquier interesado que quiera discutir la legalidad de lo concedido en la licencia por exceso o defecto sobre lo que entiende que es lo legalmente establecido deberá impugnar el acto habilitante si no quiere que el mismo sea firme. Se obliga, por tanto, a actuar al ciudadano comprometiendo su círculo vital al imponerse la interpretación de la Ley que haga en cada caso la Administración ${ }^{3}$.

Más allá de este importante asunto, la Sentencia 79/2017 aborda otras dos cuestiones de interés: la constitucionalidad del efecto suprarregional de los actos de autorización y la de la suspensión automática a la admisión de los recursos interpuestos por la Comisión Nacional de los Merados y la Competencia en defensa de la unidad de mercado.

Dado que la primera cuestión requiere un tratamiento especialmente intenso por ser, en nuestra opinión, la decisión más importante y controvertida de la sentencia que comentamos, vamos a ocuparnos ahora brevemente de lo relativo a la declaración de inconstitucionalidad de la suspensión automática de la actividad impugnada que entrañaba, según el art. 127 quater de la Ley de la Jurisdicción Contencioso-Administrativa en la redacción dada por la disposición adicional primera de la Ley 20/2013, la mera admisión a trámite de un recurso interpuesto por la Comisión Nacional de los Mercados y la Competencia (en adelante, CNMC) dirigido contra una disposición general, acto, actuación, inactividad o vía de hecho que considerase contraria a la libertad de establecimiento o de circulación.

Dicho régimen de suspensión tenía la particularidad de que bastaba que la Sala de lo Contencioso-Administrativo de la Audiencia Nacional admitiese el recurso para que, si así lo había solicitado la CNMC en su escrito de interposición, se produjese el efecto suspensivo de forma automática, sin que el Tribunal hiciese propiamente una valoración de la medida cautelar, ya que en ese momento sólo valoraría los requisitos procesales imprescindibles para admitir el recurso.

La suspensión sólo sería objeto de análisis si, pasados tres meses, la Administración afectada pedía al Tribunal la revisión de la misma por la grave perturbación a los intereses públicos o de terceros que produciría.

Sobre este asunto, de creciente importancia en nuestro sistema, vid. R. BOCANEGRA SierRa y J. GARCÍA LUENGO, «La potestad de dictar actos administrativos como intromisión en la libertad», Revista de Administración Pública, núm. 172 (2007), pp. 103 y ss. 
De esta forma se estaba poniendo en manos de la CNMC un instrumento jurídico de una intensidad notable que suponía de hecho condicionar la eficacia jurídica de los actos y disposiciones de las Administraciones que estimase contrarios a la unidad del mercado. El Tribunal Constitucional consideró, en una argumentación plausible, que esta potestad constituía un control administrativo ex post contrario al principio de autonomía, que exige que el control de la actividad de los entes que gozan de la misma se haga primariamente por los Tribunales y no por otras Administraciones.

El Tribunal entiende, correctamente, que cuando la Constitución quiere limitar los efectos de la autonomía lo hace expresamente como cuando otorga una potestad de suspensión de los actos y disposiciones impugnados por el Gobierno central ante el propio Tribunal Constitucional en el art. 161.2, que en todo caso queda a disposición del propio Tribunal.

En el caso de la potestad otorgada en el citado art. 127 quater de la Ley de la Jurisdicción Contencioso-Administrativa se trataba de un poder sin respaldo constitucional, otorgando de facto a un ente administrativo la facultad de suspender por tres meses las decisiones de otras Administraciones, sin un control judicial real y que, además, no requería siquiera una motivación de las razones que la justificaban.

Por todo ello, no es difícil compartir con el Tribunal Constitucional que esta potestad supondría «una forma de control sobre la actuación de la Administración autonómica, además de no prevista constitucionalmente, incompatible con el principio de autonomía y con la esfera competencial que de éste deriva», lo que justifica sobradamente la inconstitucionalidad del precepto que se decreta en la sentencia comentada.

\section{EN PARTICULAR, ALCANCE DE LA PROHIBICIÓN CONSTITUCIONAL DEL EFECTO SUPRARREGIONAL DE LOS ACTOS DE AUTORIZACIÓN}

El último de los temas que suscita la Sentencia 79/2017 del Tribunal Constitucional que vamos a analizar requiere un tratamiento un poco más extenso y afecta a cuestiones nucleares sobre la eficacia de los actos administrativos y de otros títulos habilitantes en el seno de un Estado complejo como es España.

El problema se suscita por el modo en el que la Ley 20/2013 refleja el que denomina, en su art. 6, principio de eficacia de las actuaciones de 
las autoridades competentes en todo el territorio nacional, y, muy concretamente, el alcance de dicha eficacia suprarregional según el art. 19 de la propia Ley 20/2013, que venía a suponer que las autoridades de destino no pudiesen exigir a los operadores económicos establecidos fuera de esa Comunidad Autónoma requisitos de acceso a una actividad económica o requisitos para la comercialización de sus bienes adicionales a los que se hayan exigido por la normativa vigente en la Comunidad de origen - aunque no existan requisitos en dicho lugar- ${ }^{4}$.

La aproximación que el Tribunal Constitucional hace a esta cuestión parte de la consideración del tratamiento que hace el Tribunal de Justicia de la Unión Europea del efecto transnacional en el ámbito del Mercado Común Europeo y, concretamente, del concepto de reconocimiento mutuo acuñado en la jurisprudencia europea a partir de la capital Sentencia de 20 de febrero de 1979 en el asunto 120/78, Cassis de Dijón.

El Tribunal Constitucional analizando dicha doctrina recuerda que el reconocimiento mutuo, siendo, como es, una manifestación capital de las libertades comunitarias, no es un derecho incondicionado, ya que, más allá de los supuestos en los que existe una norma comunitaria de armonización que ampare ese efecto transnacional, la obligación de reconocer la comercialización de un producto o servicio de otro país está limitada por la facultad de las autoridades nacionales para hacer valer exigencias imperativas, esto es, objetivos legítimos que justifican la imposición de un estándar de exigencia superior que autoriza a condicionar o prohibir la comercialización de un determinado producto o servicio no armonizado, potestad que, no obstante, debe ejercerse conforme al principio de proporcionalidad, de forma que no es legítimo prohibir la comercialización cuando el producto

${ }^{4}$ El citado art. 19, declarado íntegramente inconstitucional, tenía, bajo el título «Libre iniciativa económica en todo el territorio nacional», el siguiente tenor literal: «1. Desde el momento en que un operador económico esté legalmente establecido en un lugar del territorio español podrá ejercer su actividad económica en todo el territorio, mediante establecimiento físico o sin él, siempre que cumpla los requisitos de acceso a la actividad del lugar de origen, incluso cuando la actividad económica no esté sometida a requisitos en dicho lugar.

2. Cualquier producto legalmente producido al amparo de la normativa de un lugar del territorio español podrá circular y ofertarse libremente en el resto del territorio desde el momento de su puesta en el mercado.

3. Cuando conforme a la normativa del lugar de destino se exijan requisitos, cualificaciones, controles previos o garantías a los operadores económicos o a los bienes distintos de los exigidos u obtenidos al amparo de la normativa del lugar de origen, la autoridad de destino asumirá la plena validez de estos últimos, aunque difieran en su alcance o cuantía. Asimismo, el libre ejercicio operará incluso cuando en la normativa del lugar de origen no se exija requisito, control, cualificación o garantía alguno». 
o servicio garantiza un mismo nivel de protección aunque no se cumplan exactamente las mismas características técnicas.

El Tribunal Constitucional señala, siguiendo esta línea de argumentación, que su doctrina tradicional a la hora de valorar las exigencias de reconocimiento mutuo impuestas por la normativa interna española se ha situado en términos similares a la doctrina comunitaria y trae a colación sentencias en las que en el pasado admitió los efectos suprarregionales de actos dictados por una Comunidad Autónoma conforme a una normativa común (SSTC 87/1985, 100/1991 o 236/1991).

Partiendo de estos antecedentes, el Tribunal fija lo que considera el principio constitucional vigente en materia de reconocimiento de los efectos suprarregionales: «En la medida en que exista una normativa de la Unión Europea armonizada o una legislación estatal común o exista una pluralidad de legislaciones autonómicas que, no obstante sus posibles diferencias técnicas o metodológicas, fijen un estándar que pueda ser considerado equivalente, el Estado podrá reconocer a las decisiones autonómicas efectos extraterritoriales a través de la imposición del reconocimiento de la decisión adoptada en una determinada Comunidad Autónoma en el resto».

Como se observa, el principio así establecido está claramente inspirado en las soluciones propias del Derecho de la Unión lo que, lejos de ser criticable, entiendo que es obligado para evitar, entre otras consecuencias, que se generen discriminaciones inversas ${ }^{5}$ en contra de los productores o prestadores de servicios de otras Comunidades.

A partir de esta doctrina el Tribunal pasa a enjuiciar la solución concreta adoptada por la Ley 20/2013 y la declara inconstitucional, ya que la Ley da un tratamiento sin matices del principio de reconocimiento obligando a las Comunidades Autónomas a asumir la eficacia de los actos habilitantes dictados por otras Comunidades Autónomas sin control alguno y sin exigir la debida equivalencia en las condiciones impuestas a los operadores en la producción de bienes y servicios.

La ausencia de dicha equivalencia hace que la competencia de las Comunidades Autónomas, aunque formalmente se mantenga, materialmente se vulnere y vacíe, ya que se produce un desplazamiento de las normativas más exigentes a favor de aquellas que se caractericen por unos criterios más laxos.

5 Sobre el concepto de discriminación inversa vid. D. SARMIENTO, «Discriminaciones inversas comunitarias y Constitución Española», Revista Española de Derecho Europeo, núm. 15 (2005), pp. 375 y ss. 
Con ello, el Tribunal Constitucional está describiendo uno de los principales problemas que plantea la eficacia supraterritorial de los actos administrativos, lo que ya hace una década calificamos como dumping regulatorio ${ }^{6}$.

La consecuencia lógica de esta doctrina es la declaración de inconstitucionalidad y consecuente nulidad de los arts. 19 y 20 de la Ley 20/2013 y de varios preceptos conexos con los mismos [letras b), c) y e) del art. 18.2 y disposición adicional décima], con lo que se suprime el efecto suprarregional automático e indiscriminado de los actos habilitantes que había instaurado la citada norma.

\section{VALORACIÓN DE LA POSICIÓN DEL TRIBUNAL CONSTITUCIONAL. ¿ES SIEMPRE NECESARIA UNA NORMA DE COBERTURA DEL EFECTO SUPRARREGIONAL?}

La posición del Tribunal Constitucional ha sido objeto de diversas críticas doctrinales por considerar que desconoce las exigencias del mercado interior, reconocido en la Constitución, y no tiene en consideración la vertiente subjetiva de la eficacia suprarregional como garantía de la libertad de empresa que trata de evitar la necesidad de reiterar trámites para poder ejercer una actividad empresarial en un mercado que por disposición constitucional debe ser único ${ }^{7}$.

Sin embargo, la doctrina del Tribunal Constitucional no conduce rectamente considerada, en nuestra opinión, a una vulneración de estas exigencias - aunque es cierto que no las tiene en cuenta en su razonamiento- y toma en consideración otro aspecto que entraña notables riesgos derivado de la pluralidad regulatoria, como es el fenómeno antes referido del dumping regulatorio.

Es importante, para justificar esta afirmación, destacar qué tipo de equilibrio se alcanza si se considera sistemáticamente la doctrina del Tribunal Constitucional y se tiene en cuenta el contexto del Derecho de la Unión Europea.

${ }^{6} \mathrm{Al}$ respecto vid. R. Bocanegra Sierra y J. García Luengo, «Los actos administrativos transnacionales», Revista de Administración Pública, núm. 177 (2008), pp. 9 y ss., esp. pp. 26 y 27.

${ }^{7}$ En tal sentido vid. el trabajo ya citado del profesor Alfaro, que se puede consultar en J. Alfaro Águila-Real, «La sentencia del Tribunal Constitucional...», op. cit. 
En primer lugar debe destacarse que el Tribunal Constitucional ha consagrado tanto las exigencias materiales que tiene que cumplir una Comunidad Autónoma para establecer un régimen autorizatorio o una prohibición para la realización de una actividad económica como, en esencia, las posibilidades formales de «control» sobre las potestades de intervención. Es en este ámbito en el que se debe incidir si se quiere mejorar el funcionamiento del mercado interior ${ }^{8}$. Lo decisivo es que no existan barreras de entrada al mercado que resulten desproporcionadas en sentido amplio y que no respondan a un interés público legítimo.

Es en este último aspecto en el que hay que incidir materialmente. No se puede admitir que el mercado interior quede condicionado por cualquier tipo de interés público y por ello la necesidad de una definición del tipo de fines que puedan justificar la limitación, algo que la Ley 20/2013 hace y que el Tribunal Constitucional ampara, siendo este elemento, junto al juego del principio de proporcionalidad, la clave, en mi opinión, del problema. Con estos mimbres ya se puede tejer un entramado material que evite abusos contrario a la libre circulación y al mercado único porque se pueden cuestionar los requisitos y controles singulares, desusados o excesivos que esconden medidas proteccionistas.

El problema subyacente no es una hipótesis de laboratorio 9 . La existencia de una tentación a implantar este tipo de medidas restrictivas de la libertad de circulación en sentido amplio por parte de nuestras Comunidades Autónomas y de nuestras Administraciones en general no requiere mucha justificación, baste traer a colación la existencia de innumerables resoluciones, especialmente de los órganos administrativos encargados de resolver los recursos especiales en materia de contratos del sector público, condenando el establecimiento en los pliegos de cláusulas administrativas particulares de las llamadas cláusulas de arraigo, que deben ser sistemáticamente declaradas contrarias al derecho fundamental a la igualdad que ampara a los operadores que no tienen las condiciones de arraigo que se tratan de imponer ${ }^{10}$.

${ }^{8}$ En este punto coincidimos con la profesora Julia Ortega en su comentario sobre la Sentencia del Tribunal Constitucional 79/2017, que se puede consultar en bttp://almacendederecho.org/comentario-la-sentencia-del-tribunal-constitucional-la-ley-unidad-mercado/.

9 Como recurdan B. Lozano Cutanda e I. Fernández Puyol, «Sentencia del Tribunal Constitucional 79/2017 sobre la Ley de Garantía de la Unidad de Mercado», Diario La Ley, núm. 9.058, 2017, la Comisión en su «Informe sobre España 2017, con un examen exhaustivo relativo a la prevención y a la corrección de desequilibrios macroeconómicos» ha destacado que existen obstáculos a la actividad empresarial que desalientan la inversión y pone el acento precisamente en el bajo grado de aplicación de la Ley de Garantía de la Unidad del Mercado.

${ }^{10}$ Es el caso, sin ningún ánimo de exhaustividad, de las Resoluciones del Tribunal 
En el ámbito de la defensa de la unidad de mercado, el juego del principio de proporcionalidad y la necesidad de alegar un interés público que justifique la prohibición o sometimiento de la actividad o producto a autorización constituyen limitaciones materiales más importantes que el reconocimiento de eficacia suprarregional casi ilimitado que planteaba la Ley 20/2013 en los preceptos declarados inconstitucionales.

Obsérvese, además, que el juego de estos principios correctamente implementados llevaría a limitar notablemente los requisitos a las actividades y productos que pueden suponer un obstáculo al mercado único y, sobre todo, impone una cierta equivalencia, ya que difícilmente se podrán justificar en base a un catálogo cerrado de intereses públicos limitaciones muy diversas entre sí.

La importancia de este control sobre las limitaciones a las libertades de circulación de personas, bienes y servicios justifica que metodológicamente nos debamos preguntar, antes de valorar otros aspectos formales o materiales de una actividad administrativa, si el propio instrumento de actuación elegido por la Administración está justificado y, particularmente, si el sometimiento de una actuación a autorización en el caso concreto vulnera dichas libertades constitucionalmente reconocidas. Este test, que hoy también se exige a partir del principio consagrado en el art. 4 de la Ley 40/2015, de 1 de octubre, de Régimen Jurídico del Sector Público, es común en el Derecho comparado y, muy especialmente, en el sistema alemán ${ }^{11}$, y debe ser incorporado a nuestro sistema por partir de los mismos principios ${ }^{12}$.

El reconocimiento automático que planteaba la Ley 20/2013 es, sin embargo, un instrumento excesivo que fomenta el fenómeno al que ya nos hemos referido del dumping regulatorio, esto es, de la elección por el operador de la Administración o del subsistema menos exigente, y lleva a una

Administrativo Central de Recursos Contractuales 42/2014, de 13 de enero (en la que se declaran nulos de pleno derecho unos pliegos que valoran con más puntuación la presencia de delegaciones de la empresa en la Comunidad Autónoma donde tendría que ejecutar un contrato de cobertura informativa), y 21/2013, de 17 de enero (que igualmente declara la nulidad de pleno derecho de un pliego que establece un baremo en función del número de empleados de la empresa de seguridad en la provincia en la que debe prestar sus servicios).

${ }^{11} \mathrm{Al}$ respecto, por ejemplo, vid. H. U. ERICHSEN, «Verwaltungshandeln», en H. U. ERICHSEN y D. EhLERS (dirs.), Allgemeines Verwaltungsrecht, 12. ${ }^{a}$ ed., Berlin, De Gruyter, 2002, pp. 229 y ss., esp. p. 313, y, con matices, H. MAURER, Allgemeines Verwaltungsrecht, 18. ${ }^{a}$ ed., München, C.H. Beck, 2011, pp. 252 y ss. Este último autor es partidario de reconocer a la Administración una facultad muy amplia de actuación a través de esta forma concreta.

${ }^{12} \mathrm{Al}$ respecto vid. R. Bocanegra Sierra y J. García Luengo, «La potestad de dictar actos administrativos...», op. cit., pp. 103 y ss. 
equiparación a la baja de los instrumentos en defensa del interés público. Una cosa es que sea necesario combatir las prácticas contrarias a la libertad de empresa y otra es que se sacrifiquen las exigencias de muy diversos intereses públicos para evitar prácticas que pueden ser controladas por otros medios.

En este contexto es importante destacar no sólo que el nivel de protección necesario para determinados intereses puede variar por las más diversas circunstancias objetivas — piénsese que en el ámbito de la protección al medio ambiente hay zonas geográficas que por sus condiciones o por la ausencia de sinergias pueden permitirse un estándar muy inferior al propio de otras zonas más industrializadas o con peores condiciones naturales-, sino que es legítimo que se puedan desarrollar distintos niveles de protección de intereses públicos esenciales sin conculcar las condiciones básicas de ejercicio de la libertad de empresa. La patología se produce cuando la defensa de un interés público legítimo es sólo una excusa para proteger a un sector productivo autóctono frente a terceros, no cuando se establece un criterio que, aunque impone una restricción a la libre circulación, se encuentra justificado por cuanto se ampara en la defensa de un interés público digno de protección y resulta proporcional.

La solución que ha determinado el Tribunal Constitucional no es, además, una prohibición absoluta del principio del reconocimiento mutuo a nivel suprarregional. El Tribunal admite que se pueda entender en el seno del principio constitucional de unidad de mercado que las decisiones de una Comunidad Autónoma surtan efectos en otras, incluso al margen de la existencia de una norma armonizadora común, como podría ser el caso de la aplicación por ambas de una misma norma básica estatal. Simplemente somete este efecto a una condición, la existencia de un nivel equivalente de protección del interés público subyacente a la limitación.

Esta posibilidad de un reconocimiento de eficacia suprarregional ha sido objeto de una crítica digna de mención por la profesora Julia Orte$\mathrm{ga}^{13}$ que considera, en primer lugar, que el juego del principio del reconocimiento mutuo por equivalencia en el Derecho europeo no es tan incondicionado como se pudiera desprender de la exposición del Tribunal Constitucional y sólo opera como derivado directo de los Tratados cuando no hay una razón imperiosa de interés público que asista al Estado de destino para oponerse a dicho principio.

${ }_{13}$ En su ya referido comentario a la Sentencia 79/2017 disponible en bttp://almacende derecho.org/comentario-la-sentencia-del-tribunal-constitucional-la-ley-unidad-mercado/. 
En segundo lugar, la autora cuya posición estamos exponiendo considera que del principio de libre circulación de personas y mercancías reconocido en el art. 139 de la Constitución no se puede derivar un desplazamiento de los requisitos de acceso establecidos en una determinada Comunidad Autónoma por el mero hecho de cumplir dichos requisitos en otra.

Esta posición, brillantemente expuesta, viene a ofrecer una solución similar a la que se ha adoptado por la mayor parte de la doctrina alemana, que rechaza un efecto suprarregional de los actos administrativos habilitantes más allá del impuesto por la normativa suprarregional común ${ }^{14}$.

Sin embargo, la posición adoptada por el Tribunal Constitucional español viene a coincidir con algún planteamiento doctrinal sólido, como el de Seibert ${ }^{15}$, que se basa en la idea de lealtad institucional que debe conducir al reconocimiento de eficacia a los actos dictados con condicionantes similares por las otras administraciones del mismo Estado y, sobre todo, toma en consideración el juego de tres importantes principios constitucionales.

En primer lugar, es contrario al principio de proporcionalidad pretender que el titular del derecho a la libre circulación vuelva a someterse a un régimen de autorización cuando ha pasado un control equivalente por otra Administración.

En segundo lugar, vulnera el principio de igualdad de los operadores nacionales exigir un entendimiento del principio de libre circulación distinto al impuesto por la Unión Europea, y por más que se pueda discutir el alcance concreto de dicho principio es evidente que en el ámbito de la Unión hay una exigencia de reconocimiento automático más allá de normas armonizadoras comunes y construido a partir de la doctrina Cassis de Dijon, que, además, tiene manifestaciones concretas en la práctica cotidiana del Derecho ${ }^{16}$.

\footnotetext{
${ }^{14}$ En tal sentido vid. los autores citados por M.-J. SEIBERT, Die Bindungswirkung von Verwaltungsakten, Baden-Baden, Nomos, 1989, p. 276, nota 82.

15 Autor que entiende que en un Estado federal del principio de mutua lealtad (Bundestreue) entre los Estados federados se debe derivar la necesidad de asumir en un Estado los actos dictados por otros cuando los presupuestos para adoptar dicho acto son similares en ambos subsistemas. Al respecto vid. M.-J. SEIBERT, Die Bindungswirkung..., op. cit., pp. 286 y 288.

${ }^{16}$ Un buen ejemplo del papel que el principio de reconocimiento mutuo juega en nuestra práctica cotidiana se encuentra en la Sentencia del Tribunal Superior de Justicia de Madrid de 25 de enero de 2000 (recurso 1260/1997), que reconoce el derecho a comercializar en España un producto dietético que ha sido admitido por las autoridades italiana y al que en nuestro país se denegó la inscripción en el Registro General Sanitario de Alimentos en una decisión que el Tribunal considera contraria a la jurisprudencia Cassis de Dijon y que anula ordenando la inscripción, obligada dado el reconocimiento en Italia.
} 
En tercer lugar, el desplazamiento de la norma de la Comunidad Autónoma receptora no se hace en puridad a favor de la norma de la Comunidad de origen, sino porque el principio de libre circulación, y, sobre todo, el principio de proporcionalidad — normas estatales que gozan de primacía一, así lo imponen.

El principal problema de este planteamiento del Tribunal Constitucional viene dado por el reto que supone para la seguridad jurídica. La equivalencia es un concepto jurídico indeterminado y la existencia de un régimen de autorización taxativo, que generalmente vendrá acompañado de un arsenal sancionador, pone al operador en la difícil tesitura de asumir el riesgo de no someterse al mismo haciendo valer el título habilitante de origen. Entendemos que la ley básica podría imponer en este marco, y teniendo en cuenta la doctrina del propio Tribunal Constitucional, un mecanismo de consulta previa a las autoridades de destino sobre la «equivalencia» del título de origen que posibilitaría también un mejor control a través del proceso contencioso-administrativo de las decisiones que pongan en peligro el mercado único. 